\section{Case Reports in Neurology}

Case Rep Neurol 2021;13:233-238

DOI: $10.1159 / 000514091$

Published online: April 12, 2021
(C) 2021 The Author(s)

Published by S. Karger AG, Basel www.karger.com/crn

This article is licensed under the Creative Commons Attribution-NonCommercial 4.0 International License (CC BY-NC) (http://www.karger.com/Services/OpenAccessLicense). Usage and distribution for commercial purposes requires written permission.

\title{
Ibuprofen-Induced Aseptic Meningitis in a Male Adolescent with Intracranial Hypertension and Visual Impairment: A Case Report
}

\author{
Seyed Mohammad Mousavi Mirzaei ${ }^{a, b} \quad$ Zahra Ahmadi ${ }^{a, b}$ \\ aDepartment of Neurology, School of Medicine, Birjand University of Medical Sciences,

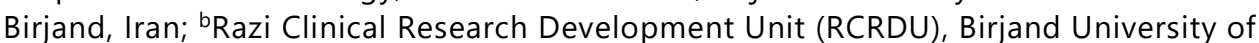 \\ Medical Sciences, Birjand, Iran
}

\section{Keywords}

Ibuprofen · Drug-induced aseptic meningitis · Intracranial hypertension · Aseptic meningitis

\begin{abstract}
Drug-induced aseptic meningitis (DIAM) is a rare complication of certain drugs, most commonly reported with ibuprofen use. The present study reports on a male adolescent with intracranial hypertension and visual impairment accompanied by DIAM. We present a 16 -yearold male patient who after ibuprofen consumption displayed headache, fever, photophobia, and blurred vision following heavy exercises. Examination of cerebrospinal fluid showed a mononuclear pleocytosis and an increase in protein concentration. Other examinations had normal results. The development of common clinical signs following ibuprofen use reflected DIAM. The patient's vision was found to improve with supportive care and stopping of the drug during follow-up. Given the widespread use of nonsteroidal anti-inflammatory drugs and the fact that these drugs are the most common cause of DIAM, the probability of occurrence of this event should be always kept in mind, and screening for autoimmune diseases in these patients is of great importance.




\section{Case Reports in Neurology}

Mousavi Mirzaei and Ahmadi: Ibuprofen-Induced Aseptic Meningitis

\section{Introduction}

Aseptic meningitis is a nonbacterial inflammation of the protective covering surrounding the brain and spinal cord [1]. Viral infection is a common cause of this disease. In addition, various infectious and noninfectious causes, such as medications, may contribute to the occurrence of the disease [2]. Ibuprofen is the most common cause of drug-induced aseptic meningitis (DIAM), and it is crucial to examine and exclude other causes [3]. The present study reports the case of an adolescent male with intracranial hypertension and visual impairment accompanied by DIAM.

\section{Case Study}

We report a 16-year-old male patient with complaints of headache and blurred vision who was admitted to the neurology ward of Razi Hospital in Birjand city. One week before the onset of symptoms, the subject had taken ibuprofen $400 \mathrm{mg} 3$ times daily to relieve back pain and muscle pain following each bout of strenuous exercise. The patient reported headache, fever, photophobia, blurred vision, nausea, and vomiting 1 week after ibuprofen use. The patient reported no history of administration of other drugs that was responsible for the increased cerebral pressure, and no ophthalmologic reasons were noted for his vision loss on ophthalmologic consultation. On clinical examination, the subject displayed a mild fever $\left(38^{\circ} \mathrm{C}\right)$, neck flexion restriction, and bilateral papilledema.

\section{Differential Diagnosis}

The results of lumbar puncture and examination of cerebrospinal fluid (CSF) showed a mononuclear pleocytosis and an increase in protein concentration after drug use (white cell count $58 / \mathrm{mm}^{3}$ [0\% neutrophils and $100 \%$ lymphocytes], total protein $125 \mathrm{mg} / \mathrm{dL}$, and glucose $85 \mathrm{mg} / \mathrm{dL}$ with blood glucose $120 \mathrm{mg} / \mathrm{dL}$ ). Other laboratory examinations including a Gram staining smear and microbial culture, cryptococcal antigen pneumococcal antigen assays, acid-fast bacteria smear and culture, India ink staining, HSV PCR, Wright agglutination test, CSF cytology, and Neuro9 PCR were reported negative. ADA and ACE were reported normal in CSF. The patient also underwent MRV and MRI with and without contrast, and the results were reported normal (Fig. 1, 2). In addition, a peripheral blood cell count, electrolyte, biochemistry, thyroid and parathyroid function, liver, kidney, vitamin B12, and serum level of lead and uric acid were normal. Tests for assessment of endocrine disorders and vasculitis were normal.

\section{Treatment}

Prior to presenting the test results, the patient was first treated with empirical ceftriaxone ( 2 g per $12 \mathrm{~h}$ ), vancomycin ( $1 \mathrm{~g}$ per $12 \mathrm{~h}$ ), and acyclovir $(750 \mathrm{mg}$ per $8 \mathrm{~h}$ ). After the infectious meningitis assessment became negative, the treatment was terminated. Within 7 days of hospital stay, the patient's headache was gone and visual acuity was reduced.

\section{Outcome and Follow-Up}

The patient's vision appeared to have improved on the 2-week and 1-month follow-up after hospital discharge. The development of common clinical signs following ibuprofen use reflected DIAM in our study case.

\section{Karger'=}




\section{Case Reports in Neurology}

Case Rep Neurol 2021;13:233-238

DOI: 10.1159/000514091

Mousavi Mirzaei and Ahmadi: Ibuprofen-Induced Aseptic Meningitis

\section{Discussion}

Aseptic meningitis is a rare side effect of ibuprofen use [3]. Although ibuprofen is the most common cause of aseptic meningitis, other nonsteroidal anti-inflammatory drugs (NSAIDs) such as diclofenac, sulindac, naproxen, ketoprofen, tolmetin, piroxicam, and two newly introduced drugs, rofecoxib and celecoxib, have been associated with aseptic meningitis [3, 4].

DIAM may present with numerous clinical symptoms. According to the literature, commonly reported symptoms following drug use were headache, fever, photophobia, blurred vision, nausea, and vomiting. Typically, the signs and symptoms of NSAID-induced meningitis appear within a few minutes, hours, or up to 4 weeks following the administration of NSAIDs. However, cases with longer delays have been reported [5, 6]. The most common symptoms associated with NSAID-induced meningitis include fever, shivering, headache, nausea, vomiting, conjunctivitis, generalized arthralgia and myalgia, and skin rashes $[3,6,7]$.

Classic symptoms of meningitis include nuchal rigidity, Kernig's and Brudzinski's signs, meningoencephalitis, and confusion [1, 6, 7]. Seizure is also commonly reported in $7-16 \%$ of cases, and some cases may display elevated white blood cell counts in peripheral blood [8, 9].

With regard to CSF results, DIAM differs across cases. Usually there is pleocytosis with high concentrations of multinucleated cells, but there are also mononuclear lymphocytes and eosinophils in CSF. The majority of DIAM patients may have normal glucose levels and increases in protein concentration and CSF pressure $[1,10]$. Due to the pleocytosis and increase in protein level after drug use, initially it may be mistaken for bacterial meningitis [6], so that multiple medications such as ceftriaxone, vancomycin, acyclovir, among others, have been prescribed until the infectious meningitis tests become negative. In our study case, the results of the CSF analysis and CSF smear excluded bacterial meningitis. Also, the results of the Neuro9 PCR, as well as the quick remission of symptoms following termination of medication, mostly excluded viral meningitis.

The causes of increased intracranial pressure have been investigated in various studies. Classic mechanisms of increased intracranial pressure include increased CSF production, decreased CSF absorption, increased cerebral venous pressure, and venous stenosis and thrombosis [10]. In our patient, brain imaging showed no signs of intracranial hypertension. Elevated intracranial pressure due to metabolic, hormonal, and autoimmune diseases such as lupus, sarcoidosis, and Behçet were suggested to the patient, but there was no abnormality in the complete hormonal and vasculitic laboratory tests. In addition, CSF cytology was negative, and the patient reported no history of other drug use; also, ophthalmologic causes were not reported on ophthalmic consultation.

Although the pathogenic mechanism by which NSAIDs cause meningeal inflammation is still unknown, it appears to be an immunologically mediated hypersensitivity mechanism, especially of type III or type IV. It has been suggested that the drug combines with a CSF or meningeal protein that acts as a hapten, leading to an inflammatory response in the meninges, thereby explaining the restricted localization of the inflammatory response to the meningeal compartment $[2,5,7,9]$.

\section{Conclusions}

DIAM is a rare complication of certain drugs, most commonly caused by anti-inflammatory drugs, especially ibuprofen. Due to wide use of NSAIDs and the fact that these drugs are

\section{Karger'=}




\section{Case Reports in Neurology}

\begin{tabular}{l|l}
\hline Case Rep Neurol 2021;13:233-238 \\
\hline DOI: 10.1159/000514091 & $\begin{array}{l}\text { @ 2021 The Author(s). Published by S. Karger AG, Basel } \\
\text { www.karger.com/crn }\end{array}$ \\
\hline
\end{tabular}

Mousavi Mirzaei and Ahmadi: Ibuprofen-Induced Aseptic Meningitis

the most common cause of DIAM, the probability of occurrence of this event should always be considered, and screening for autoimmune diseases in DIAM patients is very important.

\section{Acknowledgements}

The authors would like to thank Birjand University of Medical Sciences, Birjand, Iran, and also the Unit for Development of Clinical Research of Razi Hospital for consultation and editorial assistance.

\section{Statement of Ethics}

The data including the name of the patient used to support the findings of this study are restricted by the Birjand University Ethics Committee in order to protect patient privacy. The authors confirm to have obtained written informed consent from the parents of the patient for publication of this case report and any accompanying images.

\section{Conflict of Interest Statement}

The authors have no conflicts of interest to declare.

\section{Funding Sources}

The authors received no funding for the publication of the case report.

\section{Author Contributions}

Both authors contributed to manuscript development, its rationale, and patient management as well as the design of this article, helped to draft the manuscript, and read and approved the final manuscript.

\section{References}

1 Chaudhry HJ, Cunha BA. Drug-induced aseptic meningitis. Diagnosis leads to quick resolution. Postgrad Med. 1991 Nov;90(7):65-70.

2 Pires SA, Lemos AP, Pereira EP, Maia PA, Agro JPSEABD. Ibuprofen-induced aseptic meningitis: a case report. Rev Paul Pediatr. 2019 Jun;37(3):382-5.

3 Rodríguez SC, Olguín AM, Miralles CP, Viladrich PF. Characteristics of meningitis caused by Ibuprofen: report of 2 cases with recurrent episodes and review of the literature. Medicine (Baltimore). 2006 Jul;85(4):21420.

4 Bonnel RA, Villalba ML, Karwoski CB, Beitz J. Aseptic meningitis associated with rofecoxib. Arch Intern Med. 2002 Mar;162(6):713-5.

5 Nguyen HT, Juurlink DN. Recurrent ibuprofen-induced aseptic meningitis. Ann Pharmacother. 2004 Mar;38(3):408-10.

\section{Karger'=}


Case Reports in Neurology
Case Rep Neurol 2021;13:233-238

DOI: 10.1159/000514091

(c) 2021 The Author(s). Published by S. Karger AG, Basel www.karger.com/crn

Mousavi Mirzaei and Ahmadi: Ibuprofen-Induced Aseptic Meningitis

6 Karmacharya P, Mainali NR, Aryal MR, Lloyd B. Recurrent case of ibuprofen-induced aseptic meningitis in mixed connective tissue disease. BMJ Case Rep. 2013 Apr;2013:bcr2013009571.

7 Moreno-Ancillo A, Gil-Adrados AC, Jurado-Palomo J. Ibuprofen-induced aseptic meningoencephalitis confirmed by drug challenge. J Investig Allergol Clin Immunol. 2011;21(6):484-7.

8 Obermoser G, Bellmann R, Pfausler B, Schmutzhard E, Sepp N. Aseptic meningo-encephalitis related to dexibuprofen use in a patient with systemic lupus erythematosus: a case report with MR findings. Lupus. 2002;11(7):451-3.

9 Ashwath ML, Katner HP. Recurrent aseptic meningitis due to different non-steroidal anti-inflammatory drugs including rofecoxib. Postgrad Med J. 2003 May;79(931):295-6.

10 Ducros A, Biousse V. Headache arising from idiopathic changes in CSF pressure. Lancet Neurol. 2015 Jun;14(6):655-68.

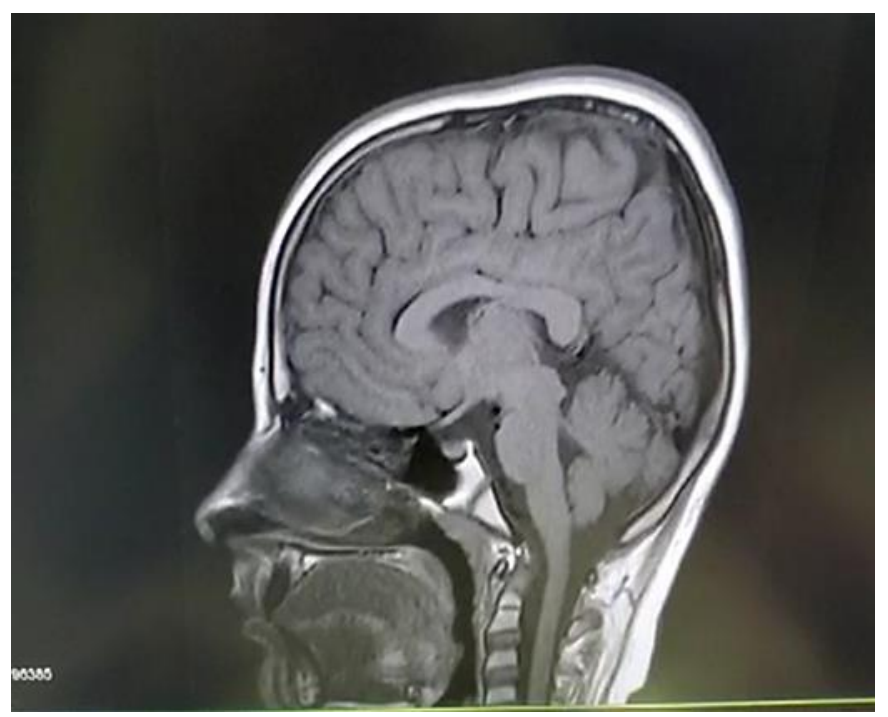

Fig. 1. Brain MRI of the patient with drug-induced aseptic meningitis. 
Case Reports in Neurology
Case Rep Neurol 2021;13:233-238 DOI: 10.1159/000514091 (c) www.karger.com/crn

Mousavi Mirzaei and Ahmadi: Ibuprofen-Induced Aseptic Meningitis

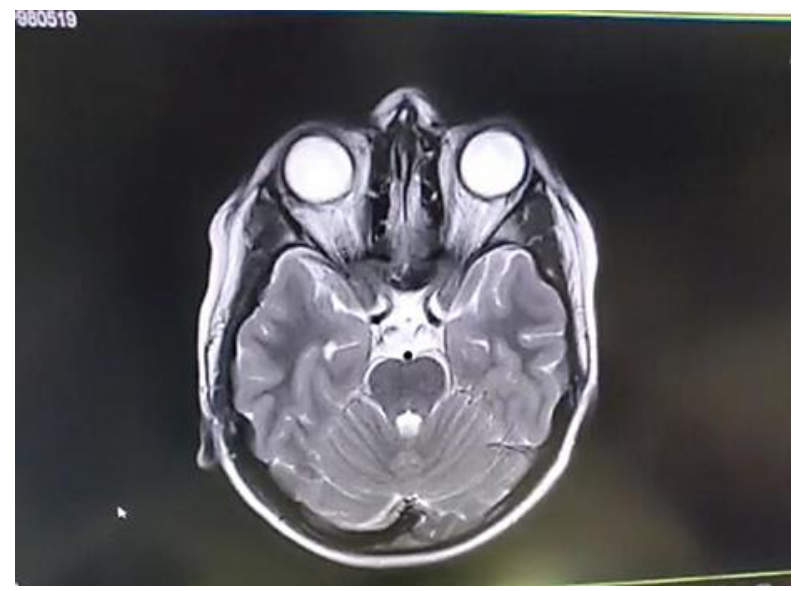

Fig. 2. Sagittal T1-weighted and axial T2-weighted cranial MRI was normal. 